\title{
PERBEDAAN KEMAMPUAN MENULIS PUISI MENGGUNAKAN MODEL PEMBELAJARAN EXAMPLE NON EXAMPLE DENGAN MENGGUNAKAN MODEL PEMBELAJARAN KONVENSIONAL SISWA KELAS VIII SMP NEGERI 7 KOTA BENGKULU
}

\author{
Rian Efrizal, Ria Ariesta, dan Didi Yulistio \\ Program Studi Pendidikan Bahasa Indonesia \\ Jurusan Pendidikan Bahasa dan Seni \\ FKIP Universitas Bengkulu \\ rianefrizal26@gmail.com
}

\begin{abstract}
Abstrak
Tujuan Penelitian ini untuk mendeskripsikan perbedaan kemampuan menulis puisi menggunakan model pembelajaran example non example dengan menggunakan model pembelajaran konvensional siswa kelas VIII SMP Negeri 7 Kota Bengkulu. Data yang diperoleh berupa hasil tes kemampuan siswa menulis puisi dengan model pembelajaran yang berbeda dan diterapkan pada kelas yang berbeda. Populasi pada penelitian ini seluruh siswa kelas VIII SMPN 7 Kota Bengkulu, dan yang menjadi sampel pada penelitian ini siswa kelas VIII D belajar dengan menggunakan model pembelajaran example non example dan siswa kelas VIII E yang belajar dengan menggunakan model pembelajaran konvensional. Metode yang digunakan pada penelitian ini menggunakan metode kuantitatif, dengan teknik pengumpulan data menggunakan tes kemampuan menulis puisi, dan dianalisis menggunakan teknik analisis uji beda atau uji " $\mathrm{t}$ ". Hasil penelitian menunjukan bahwa (1) kemampuan menulis puisi menggunakan model pembelajaran example non example hasil nilai rata-ratanya 73,47 yang termasuk dalam kategori baik, (2) kemampuan menulis puisi dengan menggunakan model pembelajaran konvensional nila rata-ratanya 60,78 yang termasuk dalam kategori cukup, dan (3) terdapat perbedaaan antara kemampuan menulis puisi menggunakan model pembelajaran example non example dengan mengggunakan model pembelajaran konvensional, dengan demikian $\mathrm{H}_{\mathrm{a}}$ diterima.
\end{abstract}

Kata kunci: Menulis, puisi, example non example, konvensional

\begin{abstract}
The purpose of this study was to describe the differences in the ability to write poetry using the example non example learning model using conventional learning models of VIII grade students of SMP Negeri 7 Kota Bengkulu. The data obtained in the form of the test results of students' ability to write poetry with different learning models and applied to different classes. The population in this study were all eighth grade students of Bengkulu City 7 Middle School, and the sample in this study students of class VIII D learned by using example non example learning model and students of class VIII E learned using conventional learning models. The method used in this study uses quantitative methods, with data collection techniques using the ability to write poetry, and analyzed using different test analysis techniques or "t" test. The results showed that (1) the ability to write poetry using the learning model example non example the average score of 73.47 which included in the good category, (2) the ability to write poetry using conventional learning models with an average score of 60.78 which included in the sufficient category, and (3) there is a difference
\end{abstract}


between the ability to write poetry using the example non example learning model using conventional learning models, thus $\mathrm{Ha}$ is accepted.

\section{Keywords: Writing, poetry, example non example, conventional}

\section{PENDAHULUAN}

Menulis merupakan aspek kebahasaan yang paling lengkap. Di mana menulis dapat dilakukan setelah mempelajari tiga aspek kebahasaan sebelumnya yaitu : menyimak, berbicara, dan membaca. Menulis merupakan kegiatan yang dapat menghasilkan suatu produk yang berbentuk sebuah karya tulis.

Kurniawan (2014:42) menulis adalah proses kegiatan menuangkan gagasan dan pengalaman yang telah dieksplorasi menjadi karya tulis kreatif. Di dalam pembelajaran bahasa Indonesia menulis terbagi menjadi dua bagian menulis fiksi dan non-fiksi. Keterampilan menulis fiksi dan non fiksi sama-sama dibutuhkan pada pembelajaran bahasa Indonesia. Salah satu bentuk dari penulisan fiksi ialah menulis puisi.

Suwarna, (2012:7) menulis puisi merupakan proses menuangkan ungakapan perasaan dari seorang penulis itu sendiri. Bentuk dari isi perasaan seseorang diwakili dengan rasa marah, kecewa, sebal, senang, kagum, dan lainlain.

Tetapi pada kenyataannya dalam pembelajaran menulis puisi merupakan kegiatan pembelajaran yang masih sukar untuk dilakukan oleh peserta didik pada jenjang (SMP) , khususnya SMPN 7 Kota Bengkulu,hal tersebut dibuktikan dengan nilai rata-rata siswa yang belum mencapai bobot nilai yang telah ditentukan oleh guru. Hal tersebut diketahui berdasarkan hasil kemampuan menulis puisi peserta didik pada kelas VIII SMPN 7 Kota Bengkulu. Belum tercapainya nilai dari peserta didik secara maksimal karena kegiatan pembelajaran dalam penyampaian materi menulis puisi yang mebuat peserta didik sulit untuk memahaminya. Pembelajaran menulis puisi di SMPN 7 Kota Bengkulu dilakukan dengan model pembelajaran konvensional atau model pembelajaran tradisional.

Menurut Muliawan (2016:16-17) pembelajaran konvensional merupakan pembelajaran klasik di mana guru hanya bercerita, murid mendengar dan mencatat atau guru yang memberi materi dan siswa hanya menerima. Pembelajaran pada metode konvesional, peserta didik lebih banyak mendengarkan penjelasan guru di depan kelas dan melaksanakan tugas jika guru memberikan latihan soal-soal kepada peserta didik. Melihat kondisi yang sedemikian model pembelajaran yang berbeda dari model pembelajaran sebelumnya merupakan strategi yang dapat digunakan untuk membantu pelaksanaan dalam kegiatan pembelajaran. Model pembelajaran harus benar-benar kreatif sehingga peserta didik tidak merasa bosan dan beranggapan kurang menarik pada suatu proses kegiatan pembelajaran, salah satunya model pembelajaran kooperatif tipe example non example.

Muliawan, (2016:89) Model pembelajaran kooperatif tipe example non example menurut pengertian bahasa berarti contoh (dan) bukan contoh. Jika diterjemahkan menurut cara kerjanya berarti model pembelajaran yang menggunakan teknik melihat gambar dan menyimpulkan atau menjelaskan konsep apa yang diperoleh siswa dari gambar tersebut (Muliawan, 2016:89). Dengan menggunakan model pembelajaran tipe example non example kegiatan pembelajaran menulis puisi terbantu dengan adanya media berupa gambar, yang dapat membantu peserta didik dalam 
berfikir kritis terhadap satu permasalahan dalam menulis puisi

Berdasarkan permasalahan yang telah diuraikan di atas, peneliti tertarik untuk mengadakan suatu penelitian yang dapat meningkatkan kemampuan menulis puisi dalam pembelajaran Bahasa Indoneisa yang berjudul "Perbedaan Kemampuan Menulis Puisi Menggunakan Model Pembelajaran Example Non Example Dengan Menggunakan Model Pembelajaran Konvensional Siswa Kelas VIII Smp Negeri 7 Kota Bengkulu".

\section{METODE}

Penelitian ini menggunakan pendekatan kuantitatif dengan metode eksperimen semu. Tempat penelitian dilakukan di kelas VIII SMP Negeri 7 Kota Bengkulu.Populasi dan Sampel dalam penelitian ini seluruh siswa kelas VIII dan sampel nya siswa kelas VIII D sebagai kelas eksperimen dan kelas VIII E sebagai kelas kontrol. Teknik yang digunakan dalam pengumpulan data yaituteknik tes. Teknik analisi data menggunakan rumus statistik uji beda atau uji " $\mathrm{t}$ ".

\section{HASIL DAN PEMBAHASAN}

Kemampuan menulis puisi dengan menggunakan model pembelajaran example non example.Keseluruhan nilai rata-rata yang dicapai oleh siswa kelas VIII $D$ yang belajar menulis puisi menggunakan model pembelajaran example non example yaitu 73,4782609 yang termasuk kedalam kategori baik. Yang artinya siswa kelas VIII $D$ dalam tes menulis puisi secara keseluruhan telah mencapai kategori baik dalam pelaksanaanya.

Kemampuan Menulis Puisi dengan menggunakan model pembelajaran konvensional terdapat keseluruhan nilai rata-rata yang dicapai oleh siswa kelas VIII E yang belajar menulis puisi menggunakan model pembelajaran konvensional yaitu 60,7826087 yang termasuk kedalam kategori cukup. Yang artinya siswa kelas VIII $E$ dalam tes menulis puisi secara keseluruhan telah mencapai kategori cuku dalam pelaksanaanya.

Perbedaan kemampuan menulis puisi menggunakan model pembelajaran example non example dengan menggunakan model pembelajaran konvensional, akan diuji menggunakan uji statistik uji " $\mathrm{t}$ " sebagai berikut:

$t^{\prime}=\frac{\overline{X_{1}}-\overline{X_{2}}}{\sqrt{\frac{s_{1}^{2}}{n_{1}}+\frac{s_{2}^{2}}{n_{2}}}}$

$$
\begin{aligned}
& t^{\prime}=\frac{73,47-60,78}{\sqrt{\frac{90,01}{23}+\frac{210,67}{23}}} \\
& t^{\prime}=\frac{12,69}{\sqrt{3,91+9,15}} \\
& t^{\prime}=\frac{12,69}{\sqrt{13,06}} \\
& t^{\prime}=\frac{12,69}{3,61} \\
& t_{\text {hitung }}{ }^{\prime}=3,51
\end{aligned}
$$

Dengan kriteria pengujiannya adalah tolak $\mathrm{H}_{0}$ jika $t_{\text {hitung }}>t_{\text {tabel. }}$. Jika $t_{\text {hitung }}$ $\geq t_{\text {tabel }}$ maka $\mathrm{H}_{\mathrm{a}}$ diterima dengan $\mathrm{dk}=\mathrm{n}_{1}-1$ atau $\mathrm{dk}=\mathrm{n}_{2}-1$ (sugiyono, 2015:142). Dimana $t_{\text {hitung }}$ sebesar 3,51 sedangkan $t_{\text {tabel }}$ dengan $\mathrm{dk}=\mathrm{n}_{1}-1$ maka $\mathrm{dk}=23-1=22$. Jadi $t_{\text {tabel }}$ sebesar 2,07 .

Selanjutnya $t_{\text {hitung }}$ dibandingkan dengan nilai $t_{\text {tabel }}$ pada daftar distribusi $t$ dengan taraf signifikan $5 \%$ pada derajat kebebasan $d k=n-1,23-1=22$. Dengan demikian $t_{\text {hitung }}(3,51)>t_{\text {tabel }}(2,07)$ untuk taraf signifikan $5 \%$.

Hal ini menunjukkan terdapat perbedaan antara hasil kemampuan siswa menulis puisi menggunakan model pembelajaran example non example dengan menggunakan model pembelajaran konvensional, hal tersebut 
dibuktikan dengan $t_{\text {hitung }}>t_{\text {tabel }}$ untuk taraf signifikan antara $5 \%$

Dengan ini membuktikan bahwa pada penggunakan model pembelajaran example non example yang menggunakan media gambar dalam proses pembelajarannya mendapatkan hasil kemampuan menulis puisi yang lebih baik dari hasil kemampuan menulis puisi dengan menggunakan model pembelajaran konvensional.

Hasil tersebut sangat sesuai dengan teori kerucut pengalaman yang dikemukakan oleh Edgar Dale bahwa hasil belajar seseorang diperoleh melalui pengalaman langsung (kongkrit), kenyataan yang ada dilingkungan kehidupan seseorang kemudian melalui benda tiruan, sampai kepada lambang verbal (abstrak).

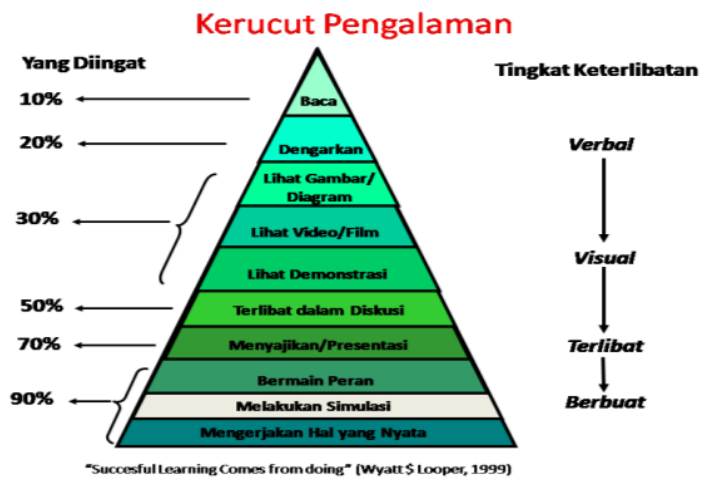

Dari gambar kerucut pengalaman diatas, gambar tersebut menjelaskan tentang suatu pengalaman pada proses pembelajaran akan lebih mudah diingat dan diserap melalui aspek verbal, visual, terlibat, dan berbuat yang dalam hal ini terdapat pada model pembelajaran example non example, seperti : mendengarkan, melihat gambar, terlibat dalam diskusi, mengerjakan hal yang nyata. Berbeda dengan model pembelajaran konvensional yang hanya menggunakan tingkat keterlibatan verbal dan berbuat seperti mendengarkan dan mengerjakan hal yang nyata.

\section{Penutup \\ Kesimpulan}

1. Kemampuan menulis puisi dengan menggunakan model pembelajaran tipe example non example pada siswa kelas VIII D SMP Negeri 7 Kota Bengkulu berkategori baik dengan nilai rata-rata sebesar 73,4782609.

2. Kemampuan menulis puisi dengan menggunakan model pembelajaran tipe konvensional pada siswa kelas VIII E SMP Negeri 7 Kota Bengkulu berkategori cukup dengan nilai ratarata sebesar 61,0434783

3. Terdapat perbedaan kemampuan siswa menulis puisi dengan menggunakan model pembelajaran example non example pada siswa kelas VIII D dengan kemampuan siswa menulis puisi menggunakan model pembelajaran konvensional pada siswa pada kelas VIII E di SMP Negeri 7 Kota Bengkulu. Dengan nilai 73,4782609 berkategori baik model dengan model pembelajaran example non example, 61,0434783. Berkategori cukup dengan model pembelajaran konvensional.

\section{SARAN}

1. Bagi Guru, dapat menjadikan hasil penelitian ini sebagai panduan dalam pembelajaran menulis puisi menggunakan model pembelajaran yang tepat sehingga menghasilkan nilai yang lebih baik seperti menggunakan model pembelajaran example non example.

2. Bagi Sekolah, sebagai bahan pertimbangan dalam merencanakan pelaksananan proses pembelajaran agar dapat meningkatkan kualitas proses dan hasil pembelajaran Bahasa Indonesia.

3. Peneliti selanjutnya, agar melakukan riset lebih luas tentang kemampuan 
menulis lainnya dengan metode pembelajaran atau tipe yang lain yang lebih sesuai dengan sumber data yang lebih banyak.

\section{DAFTAR PUSTAKA}

Kurniawan, Heru. 2014. Pembelajaran Menulis Kreatif. Bandung: PT Remaja Rosdakarya Offset.

Muliawan, Jasa Ungguh. 2016. 45 Model Pembelajaran Spektakuler.
Sugiyono. 2006. Metode Penelitian Pendidikan Pendekatan Kuantitatif dan R\&D. Bandung: Alfabeta.

Suwarna, Dadan. 2012. Trik Menulis Puisi, Cerpen, Resensi Buku, Opini/Esai. Tanggerang: Jelajah Nusa

Waluyo, Herman J. 1987. Teori Dan Apresiasi Puisi. Surakarta: Penerbit Erlangga.

Yogyakarta: Ar-Ruzz Media 